\title{
Proceeding
}

Supplementary Issue: Winter Conferences of Sports Science. Costa Blanca Sports Science Events, 22-23 March 2021. Alicante, Spain.

\section{Sudden cardiac death and coronary artery anomalies in the athletes: A narrative review}

\author{
ROBERTO BIANCO, GIADA ANNARUMMA , AMOS COSIMO COCOLA, FELICE SIRICO, VERONICA \\ ROMANO \\ Department of Public Health, University Federico II of Naples, Italy
}

\begin{abstract}
Sudden cardiac death (SCD) in the athletes is an unexpected dramatic event. The mechanism underneath SCD is often represented by a ventricular tachyarrhythmia arising as complication of a broad spectrum of cardiovascular diseases, with a silent clinical course. Therefore, SCD often represents the onset manifestation of an underlying heart disease. To prevent SCD in the athletes, several international guidelines proposed pre-participation screening protocols to identify high-risk subjects. Behind atherosclerotic diseases, other structural or functional conditions have been related to SCD, such as hypertrophic cardiomyopathy, QT-long syndrome, arrhythmogenic right ventricular dysplasia, and others. Among these, the coronary artery anomalies represent almost the $20 \%$ of all cases. The coronary artery anomalies can be classified into anomalies of origin, course and termination and can be isolated or associated with other congenital cardiac defects. Some of them are rarely symptomatic. Others could impair heart function and determine SCD. Some others determine secondary cardiovascular diseases such as increased risk of endocarditis, secondary aortic valve diseases, myocardial ischemia, and others. Innovative diagnostic and therapeutic options allowed to recognize the different coronary artery anomalies, preventing SCD in athletes. The aim of this review was to analyse coronary artery anomalies to understand their implications in SCD in athletes.
\end{abstract}

Keywords: Coronary artery; Sudden cardiac death; Athletes.

Cite this article as:

Bianco, R., Annarumma, G., Cocola, A.C., Sirico, F., \& Romano, V. (2021). Sudden cardiac death and coronary artery anomalies in the athletes: A narrative review. Journal of Human Sport and Exercise, 16(3proc), S1358S1372. https://doi.org/10.14198/ihse.2021.16.Proc3.52

Corresponding author. Department of Public Health, University Federico II of Naples, Italy.

E-mail: giada.annarumma@gmail.com

Abstract submitted to: Winter Conferences of Sports Science. Costa Blanca Sports Science Events, 22-23 March 2021. Alicante, Spain.

JOURNAL OF HUMAN SPORT \& EXERCISE ISSN 1988-5202.

(c) Faculty of Education. University of Alicante.

doi:10.14198/jhse.2021.16.Proc3.52 


\section{INTRODUCTION}

Sudden cardiac death (SCD) of a young athlete during sports is an event of high emotional impact, unexpected, dramatic and psychologically devastating for the entire community (Corrado et al., 2003). Sports SCD can be defined as "a death that occurs within one hour of the onset of acute symptoms, in temporal coincidence with sports activity, and in the absence of external causes capable of causing it" (Zeppilli, 1983).

The causes of cardiac arrest in young athletes have multiple anatomical substrates, the most represented being hypertrophic cardiomyopathy in the USA, followed by congenital anomalies of the coronary arteries, rupture of the aorta and coronary atherosclerosis (Maron et al. 1996). Hypertrophic cardiomyopathy is characterized by an abnormal extracellular matrix (ECM) turnover leading to myocardial fibrosis, an event accompanying most forms of myocardial diseases, suggesting that ECM changes could be involved in progression of the disease (Belviso et al., 2020a, 2020b; Castaldo et al., 2013). Arrhythmogenic right ventricular heart disease is the leading cause in Italy, followed by both acquired and congenital heart disease (Corrado et al., 1990), mitral valve prolapse, conduction tissue pathology and myocarditis. Among congenital diseases affecting the heart, post-mortem and retrospective studies historically reported a prevalence of 1 $2 \%$ (Roberts, 1986) of congenital anomalies of the coronary arteries (Yamanaka and Hobbs, 1990). However, in recent studies, the prevalence of these anomalies is $0.44 \%$ (Angelini et al., 2018).

The congenital anomalies of the coronary arteries represent an heterogeneous groups of conditions, and some of them play a non-negligible role in SCD among athletes (Frescura et al., 1998; Maron et al., 2009), increasing the risk of death during exertion of about 79 times (Corrado et al., 2003).

Two-thirds of athletes with congenital anomalies of the coronary arteries are asymptomatic (Basso et al., 2000), but some have syncope or SCD as the only manifestation (Van Hare et al., 2015).

The congenital anomalies of the coronary arteries cause SCD more frequently in young athletes (Harmon et al., 2015), and less commonly in individuals older than 40 years of age (Gräni et al., 2018).

This review aims to analyse the anomalies that have the greatest impact on SCD, classifying them for simplicity into anomalies of origin, course and termination.

\section{NORMAL ANATOMY OF THE CORONARY ARTERY SYSTEM}

\section{Left coronary artery}

The heart is supplied by the right and left coronary arteries, which originate from the ascending aorta, in particular from the anterior and left posterior Valsava sinuses. The arterial circulation has the shape of an inverted crown arranged obliquely along the cardiac axis, consisting of the intersections of the marginal arteries on the acute and obtuse margins, and the descending arteries at the apex.

The first section of the left coronary artery (LCA) is called the common trunk and runs in the epicardium between the pulmonary trunk and the left atrium. It originates from the left anterior aortic sinus of Valsalva and is usually $1-2 \mathrm{~cm}$ long. In two thirds of cases it divides below the left auricle into anterior descending (AD) artery and circumflex artery (CA), in one third of cases an intermediate artery arises thus forming a trifurcation that follows the path of a circumflex branch (Edwards et al., 2010). 
The AD artery is one of the two main components of the LCA (Angelini et al., 1999). It supplies the anterolateral myocardium, apex, and interventricular septum, covering the $45-55 \%$ of the left ventricular mass and it is therefore considered the most critical vessel in terms of myocardial blood supply.

It passes to the left of the common trunk of the pulmonary artery and continues anteriorly in the anterior interventricular sulcus to the apex of the heart (Brown and Borger, 2019). The AD can be divided into a proximal segment (from the origin to the origin of the first septal perforator), a middle segment (from the first septal perforator origin halfway to the left ventricular apex) and a distal segment (from this halfway point to the apex itself). Its normal length is from $10 \mathrm{~cm}$ to $13 \mathrm{~cm}$ (Villa et al., 2016). The anterior descending artery gives rise to two groups of branches: the diagonal branches and the septal branches. The diagonal branches of the $A D$ artery usually supply the anterior wall of the left ventricle. The number and course of the diagonal branches is variable; there is usually at least one diagonal branch. The septal branches arise perpendicularly from the ventral portion of the $A D$ artery. They are smaller in size than the diagonal branches and provide vascularity to the anterior two-thirds of the interventricular septum (Brown and Borger, 2019). The terminal part of the $A D$ artery surrounds the apex of the heart and supply the lower portion of the left ventricle. The $A D$ terminates at the cardiac apex, or 1 to $2 \mathrm{~cm}$ before or after the apex (Angelini et al., 1999). In some subjects, the right coronary artery is larger, and its distal branches reach the apex of the heart.

\section{Right coronary artery}

The Right Coronary Artery (RCA), which can be principally considered the artery that supplies the right side of the heart, generally arises from an ostium located just below the sinotubular junction, in the middle of the right anterior sinus of Valsalva of the ascending aorta (Angelini et al., 1999).

It passes anteriorly and to the right between the right auricle and the pulmonary artery and then dips down almost vertically in the right atrioventricular sulcus. When the RCA reaches the acute margin of the heart, it continue posteriorly in the sulcus toward the junction of the atrial and ventricular septa, the so called crux cordis, often terminating in the circumflex branch of the left coronary artery (Villa et al., 2016).

The RCA, which usual length varies from $12 \mathrm{~cm}$ to $14 \mathrm{~cm}$, provides branches to the right atrium and ventricle, the atrioventricular septum and portions of the left chambers.

It is divided into proximal, middle, and distal segments. The proximal segment goes from the origin halfway to the acute margin. The middle segment runs from this halfway point to the acute margin itself. The distal segment goes from the acute margin to the base of the heart at the junction of the atrial and ventricular septa (Macdonald et al., 2011). In 50-60\% of individuals, a conus branch arises as the first branch of the RCA to supply the right ventricular outflow tract. The conus branch, sometimes defined "third coronary artery" can serve as an important source of collateral supply to the left anterior descending artery through the so-called "circle of Vieussens" (Angelini et al., 1999). The second branches usually consist of the sinoatrial node artery and several anterior branches that supply the free wall of the right ventricle (Kim et al., 2006). The sinus node artery originates from the right (66\% of the cases) and passes in the groove between the right auricle and the ascending aorta surrounding the base of the superior vena cava to supply the sinus node and both atria (Villa et al., 2016).

The branch to the right ventricle at the junction of the middle and distal RCA is called the acute marginal branch (Kim et al., 2006). The right marginal branch arise as the RCA approaches the acute margin of the heart and continues along this border toward the cardiac apex and it supplies the right ventricle free wall (Kim et al., 2006). 
In the majority $(80 \%)$ of individuals, the RCA continues forwards from the crux along the posterior interventricular groove to become the posterior descending artery, running to the apex of the heart. This is by convention called RCA dominance (Geuns and Cademartiri, 2005). The atrioventricular nodal branch is a small branch to the atrioventricular node; the posterior interventricular branch is the final major branch, which lies in the posterior interventricular sulcus (Villa et al., 2016).

\section{CORONARY ARTERY ANOMALIES ANOMALIES OF ORIGIN}

\section{High take-off}

The origin of the RCA or LCA may be above the aortic cusps or above the sinotubular junction. Both ostia in $6 \%$ were found above the sinotubular junction (Edwards and Vlodaver, 1971) but the most affected is RCA (Frescura et al., 1998).

The cause of the high origin of the coronary arteries is due to malrotation of the aortic root in embryonic development which involves a deviation of the coronary artery with a reduction in diastolic flow important for the purpose of myocardial perfusion (Dotan et al., 2013).

Some patients have typical or atypical symptoms of angina with exercise, others may have SCD (Basso et al., 2000).

\section{Coronary ostial atresia}

It is defined as the absence of the left main ostium with the AD and CA connected but ending blindly and supplied by the right coronary artery (RCA) via collaterals. The common trunk may be normal, hypoplastic, or atretic. The clinical presentation is non-specific and widely variable depending on the degree of collateral circulation and myocardial perfusion. Some patients become symptomatic early in life, mostly with congestive heart failure and syncope, whereas others remain asymptomatic into late adulthood, before presenting mainly with angina. Sometimes the first presentation reported of this anomaly is a sudden cardiac death (SCD) (Alsalehi et al., 2019).

It is a rare anomaly, difficult to diagnose (goes into differential diagnosis with ALPACA). Non-conservative treatment is recommended in symptomatic patients, i.e. myocardial revascularization with coronary reconstruction osteoplasty (Alsalehi et al., 2019).

\section{Ostial plication}

Another condition associated with SCD is ostial plication, a stenosis of the coronary ostium attributable to a valve-like ridge as a consequence of a fold in the elastic tunica media of the aorta. Plication of the aortic wall leads to a "valve-like" ridge that can act as a door blocking inflow during diastolic filling. Consequent ischemia may produce a life-threatening arrhythmia (De-Giorgio and Arena, 2010). The surface area of the ridge must exceed $50 \%$ of the coronary ostial lumen to be related to sudden death (Virmani et al., 1984).

\section{Single coronary artery}

The origin of a single coronary artery is an extremely rare anomaly present in $0.0024-0.044 \%$ of the population (Desmet et al., 1992). The anomaly is defined as the origin of a single arterial coronary trunk from a single ostium which can be the left or right Valsalva sinus and then divides (Villa et al., 2016). It can also be classified according to the anatomical course: "type l" follows the normal course of the left or right coronary; "type II" has an abnormal origin from the proximal segment of the other coronary artery; "type III" is 
characterized by a single artery originating from the right Valsalva sinus with descending-anterior and circumflex originating from the common trunk (Lipton et al., 1979).

Although the abnormalities are usually benign, if the course of the right coronary artery is between the pulmonary artery and the aorta it can cause myocardial ischemia and SCD (Yurtdas and Gülen, 2012).

The proximal stenosis at the origin of the single trunk is critical due to the impossibility of forming collateral circles (Nieman et al., 2001).

\section{Anomalous origin of the coronary artery from the pulmonary artery}

The anomalous origin of the coronary arteries can occur from the pulmonary artery at different levels: from the trunk or from the right or left main branches.

The possible anomalous origins are: i) left coronary artery from the main trunk of the pulmonary artery or from the main branches; ii) CA from the pulmonary trunk or main branches ; iii) left and right coronary artery from the pulmonary trunk.

The most common form of this type of anomaly is the origin of the left coronary artery from the pulmonary artery and the right coronary artery from the aorta which is known as Bland-White-Garland syndrome (Bland et al., 1933). The anomaly is estimated at 1 in 300,000 births (Dodge-Khatami et al., 2002).

In this syndrome, myocardial blood supply occurs by means of collateral circulation between the left and right coronary arteries with inversion of the flow towards the pulmonary artery.

The abnormal origin of the coronary artery from the pulmonary artery then generates a left-to-right shunt.

The shunt causes blood flow to the myocardium that becomes dependent on the coronary artery originating from the aorta.

If the collateral circulation does not allow a good myocardial circulation and the patients are not treated, they do not reach the first year of life and this event occurs in $90 \%$ of cases. Consequently, few patients have a well-developed collateral circulation that allows survival to adulthood (Wesselhoeft and Fawcett, 1968).

During foetal life, this anomalous origin is tolerated as pulmonary and systemic pressures are similar. At birth, there is a drop in pulmonary pressure and an increase in systemic pressures, consequently the blood coming from the left artery decreases and there is a reversal of the flow which can be the cause of myocardial ischemia.

The diagnostic suspicion is based on growth delays, pallor, dyspnoea. On auscultation there is a continuous murmur. Ischemic changes are present in the resting ECG. It is useful to complete diagnostic assessment with heart ultrasound and Doppler examination to evidence the coronary ostia and a continuous flow in the pulmonary artery (Swensonn et al., 1988).

These anomalies are usually asymptomatic with a high risk of SCD, chest pain or arrhythmias (Corrado et al., 2006). 
Surgical treatment is always indicated and aims to re-create the double coronary circulation, through different approaches (ligation of the anomalous coronary artery, coronary reimplantation, Takeuchi procedure, direct reimplantation of the left coronary artery into the aorta) (Dodge-Khatami et al., 2002; Lange et al., 2007).

\section{Origin of the coronary artery or branch from the opposite or noncoronary sinus and anomalous course}

The prevalence of this anomaly is $0.9-0.11 \%$ in the general population, identified with traditional coronary angiography (Danias et al., 2001; Desmet et al., 1992).

There are four variants of anomalous origin from the opposite sinus:

1. the RCA originating from the left coronary sinus.

2. the LCA originating from the right coronary sinus.

3. the $C A$ or $D A$ originating from the right coronary sinus.

4. the LCA or the RCA (or a branch of an artery) originating from the non-coronary sinus.

A coronary artery that arises from the contralateral sinus of Valsalva can take five paths to its perfusion territory:

1) Pre-pulmonary: anterior to the right ventricular outflow tract; it is generally not haemodynamically significant and seldom associated with angina. This anomaly usually involves the LMCA and it is often found in tetralogy of Fallot;

2) Retro-aortic: Posterior to the aortic root. It passes posteriorly and into the space between the posterior sinus of Valsalva and the interatrial septum, where normally there are no vascular structures. This variant does not seem haemodynamically significant but may complicate surgery of the cardiac valves. This anomaly usually involves an artery arising from RCA or right sinus of Valsalva that supplies the distribution of LCA or CA artery;

3) Inter-arterial: Between the aorta and pulmonary artery. This course has been recognized as having serious prognostic implications associated with more severe prognosis and increased risk of SCD especially in young individuals. One hypothesis is based on the fact that exercise leads to expansion of the aortic root and pulmonary trunk and this may increase the existing angulation of the coronary artery, decreasing the luminal diameter. Moreover, the vessel is often hypoplastic with an aberrant course within the aortic wall and it is exposed to a lateral compression over the entire proximal intramural tract (intussusception into the aortic wall). However, in these patients, resting electrocardiograms are usually normal and stress tests are not always positive for inducible ischaemia (Angelini et al., 2002);

4) trans-septal: The coronary artery takes a subpulmonic course. The artery traverses anteriorly and inferiorly through the interventricular septum and takes an intramyocardial course, giving off septal branches and finally emerging at its normal epicardial position. The arteries most commonly involved are the AD or LCA.

This anomaly is characterized by the hammock sign, which refers to the "downward dip" that the coronary artery makes as it traverses below the level of pulmonic valve in the septal myocardium. With anomalous transseptal course, the coronary artery arises from the contralateral artery or cusp, courses downward and forward in the interventricular septum followed by an upward and leftward course as it emerges out in the anterior interventricular groove (Moore and Agarwal, 2014). 
5) retro-cardiac: the path is in the posterior AV groove, behind mitral and tricuspid valves. The clinical relevance of this coronary anomaly lies in the fact that the atypical origin and course causes coronary arteries to develop atherosclerosis more easily.

In about $15 \%$ of patients with CAAs, myocardial ischemia can develop in the absence of atherosclerosis. In addition, some potential mechanisms have been proposed to explain ischemia and SCD: spasm of the anomalous coronary artery (possibly as a result of endothelial injury or ischemia caused by its long distance), acute angle of take-off of the anomalous vessel (which may become kinked and occluded during exercise) and the related slit-like orifice (Angelini et al., 2002).

\section{ANOMALIES OF COURSE}

\section{Myocardial bridging}

Normally, in human hearts, coronary arteries and their branches run in the loose connective tissue of the subepicardial space (Angelini et al., 1999). In myocardial bridging, a portion of epicardial coronary artery, known as a tunnelled segment, passes through the myocardium for a short part before re-entering the epicardial fat. The length of the myocardial bridge most often varies between 10-50 mm (Villa et al., 2016). It then branches normally and terminates within the myocardium (Angelini, 2007). This congenital coronary anomaly results in systolic compression and remains clinically silent in the majority of cases. Any epicardial artery can be affected but bridging of the middle segment of the left anterior descending is the most common; occasionally the circumflex, diagonals, and right coronary artery (RCA) are also involved (Corban et al., 2014). Since the myocardial bridging prevalence varies between $0.15 \%-25 \%$ angiographically and $15 \%-86 \%$ at autopsy, its frequency in the general population suggests that it should be considered a normal variant (Angelini et al., 1999; Angelini, 2007; Villa et al., 2016), rather than an anomaly (Ghosh et al., 1994).

However, the prevalence of myocardial bridges varies greatly based on the technique used, highlighting the importance of differentiating a significant functional finding from an anatomic finding. In incomplete myocardial bridging, the involved artery extends down to and touches the myocardium but does not completely enter before extending back up into the myocardium. Complete myocardial bridging is seen in up to $20 \%$ of asymptomatic patients and is a very rare cause of ischemia However, rare cases of myocardial bridging are related to ischemia and atypical angina or even death (Tio et al., 1997). Possible causes are endothelial dysfunction, a delay in diastolic reopening of the intramyocardial segment of the artery that was compressed during systole and a deeper intramyocardial course of the bridge, in contrast to the more benign superficial myocardial bridges (Ferreira et al., 1991; Kumari et al., 2011; Morales et al., 1993). In addition, there is a high prevalence (41\%) of myocardial bridging in adults with hypertrophic cardiomyopathy ( $\mathrm{HCM})$ (Sorajja et al., 2003). In these patients, the myocardial bridge tends to be deep, but it does not appear to influence prognosis and the risk of sudden events death in adults (Basso et al., 2009; Olivotto et al., 2009). Therefore, in asymptomatic adults' patients with $\mathrm{HCM}$, the myocardial bridge appears to be a benign condition that does not warrant any treatment.

However, the myocardial bridging has not been ruled out as a possible cause of ischemia and sudden death in younger individuals with $\mathrm{HCM}$. Treatment with stent implantation, coronary artery bypass surgery or surgical unroofing via supra-arterial myotomy may improve quality of life in adult symptomatic patients with HCM and myocardial bridging, as well as reduce risk of SCD and alleviate symptoms in younger patients (Basso et al., 2009). 
On the other hand, patients with coronary anomalies or myocardial bridging may be at increased risk of ischemia during exercise, when there is an increased oxygen demand and ischemia could also favour arrhythmic risk in such a context. Therefore, it is quite crucial to identify for each patient what is the level of exercise that could be beneficial and when the risk of adverse events could overcome the advantages. Athletes-patients with myocardial bridging requiring treatment, even beta-blockers only, should be excluded from participating in competitive sports and should be adequately informed about recreational activities (Castelletti and Crotti, 2020).

\section{ANOMALIES OF TERMINATION}

\section{Coronary artery fistula}

A coronary fistula (CAF) or coronary arteriovenous fistula is a congenital or acquired abnormal vascular communication of the coronary arteries with the pulmonary artery, coronary sinus, cardiac chamber, or the superior vena cava, without an interposed capillary bed. Fistulas which end in the right heart chambers represent about $60 \%$ of cases.

CAFs are uncommon coronary artery abnormalities (McNamara, 1969) and can be classified according to their origin or drainage site: RCA is the most common origin site of CAFs, being the $50 \%-55 \%$ of cases. AD represents about the $35 \%-40 \%$ of cases, and CA accounts the $5 \%-20 \%$ cases (Gowda et al., 2006). The prevalence of CAFs originating from both the RCA and the AD is reported to be as high as $59 \%$ in cases of coronary-pulmonary fistula (Kim et al., 2010).

The prevalence of CAFs observed on computed tomographic angiography is $0.9 \%$ of congenital heart disease, which is higher than the previously reported prevalence of $0.002 \%-0.3 \%$ at invasive angiography (Vavuranakis et al., 1995).

The causes of CAFs are either congenital or acquired (Challoumas et al., 2014). During foetal development, sinusoids nourish the primitive myocardium, then in adulthood, sinusoids become obliterated into the thebesian vessels and capillaries. Sinusoids that don't regress may contribute to a fistulous communication between the coronary arteries and cardiac chambers, that is, a coronary cameral fistula (Challoumas et al., 2014; Rittenhouse et al., 1975). Therefore, a remnant connection between coronary arteries and other mediastinal vessels (bronchial, pericardial, or mediastinal arteries) or the superior vena cava may cause a coronary arteriovenous fistula (Baroldi et al., 1956).

The acquired forms of CAFs are rare, but the incidence is increasing; they result from iatrogenic events such as coronary stent placement, coronary bypass surgery, trauma, chest irradiation (Luo et al., 2006; Mangukia, 2012), coronary vasculitis and myocardial infarction (Yu et al., 1986).

Small size fistulas (especially those that drain into the main pulmonary artery and the left ventricle) are much more common and are asymptomatic; however, many coronary artery fistulae continue to enlarge over time and eventually cause ischemia, or the deprivation of oxygen-rich blood to the heart tissues, which may cause fatigue and/or dyspnoea during exertion (Latson, 2007).

CAFs with large intracardiac shunts are rare in adults, as are most detected and repaired in childhood. These patients with larger CAFs show an unexplained loud continuous heart murmur or abnormalities at ECG or at chest radiography (Latson, 2007). 
The amplitude of the shunt is determined by the size of the fistula and the pressure difference between the coronary artery and the drainage zone (Qureshi, 2006).

CAFs pathophysiology is caused by resistance of the connection, on the site of fistulous termination. Since the blood bypasses the myocardium and the perfusion distal decreases, a coronary steal phenomenon occurs, provoking angina or myocardial ischemia, during exercise or other activities that increase the oxygen demand.

Moreover, it should be stenosis of side branches secondary to thrombus associated with fistulous tracts, ulcerations and atherosclerosis (Vitarelli et al., 2002).

With a left-to-right shunt, CAFs drains into the systemic circulation and blood volume increases in right heart structures, pulmonary vessels, and left heart structures, causing pulmonary hypertension and volume overload in both ventricles. Conversely, the CAFs drains into the left atrium or pulmonary vein, and the risk of left heart volume overload increases.

Patients may become symptomatic, usually in the 5th or 6th decade of life, depending on the severity of the left-to-right shunt. Various symptoms, including moderate dyspnoea, fatigue, angina, congestive heart failure, and myocardial infarction, have been reported (Shiga et al., 2008). CAFs are also associated with atrial fibrillation, ventricular tachyarrhythmia (Heart et al., 2010; Kugelmass et al., 1992), valvular regurgitation (Morgan et al., 1972). In the $3 \%-12 \%$ of CAFs patients' infective endocarditis may occur.

Symptomatic patients with large fistulae may develop arrhythmias and heart failure. In these cases, surgical closure of the fistulae at the drainage site is recommended. Closure of a coronary artery fistula may be achieved through surgery or with the use of a coil or occlusion device introduced through a catheterization procedure.

While there are no exercise restrictions for patients with small CAFs with negligible symptoms, they have to be monitored regularly by a cardiologist to avoid developing arrhythmias, ischemia or heart failure. Patients with CAFs have a slightly higher risk than healthy ones of ectopic beats or sudden death during extreme exertion, for example during athletic competitions. Therefore, they should undergo a comprehensive preparticipation screening before these activities (Castelletti and Crotti, 2020).

\section{CONCLUSIONS}

Athletes with congenital anomalies of coronary arteries could be asymptomatic or present with chest pain, dyspnoea, palpitations, syncope (Ricci et al., 2018), and develop ventricular fibrillation, myocardial infarction or even SCD, especially during exercise.

For several years, traditional angiography has been the gold standard for the study of coronary arteries, with excellent sensitivity in demonstrating the origin and course of coronary arteries. Non-invasive methods for the evaluation of coronary artery anomalies includes transoesophageal echocardiography, transthoracic echocardiography (Ricci et al., 2020), multilayer computed tomography and magnetic resonance.

Especially in the so-called "athlete's heart" (D'Andrea et al., 2020), the delay in diagnosis of silent coronary anomaly may be fatal. Therefore, early identification of patients with a coronary anomaly is crucial as they 
can be saved by appropriate therapy and join a particular form of physical activity, that has several benefits in cardiovascular patients (Palermi et al., 2020).

\section{REFERENCES}

Adriana DM Villa, Eva Sammut, Arjun Nair, Ronak Rajani, Rodolfo Bonamini, A. C. (2016). Coronary artery anomalies overview: The normal and the abnormal. In World journal of radiology: Vol. June 28; 8. https://doi.org/10.4329/wjr.v8.i6.537

Alsalehi, M., Jeewa, A., Wan, A., Contreras, J., Yoo, S. J., \& Laks, J. A. (2019). A case series of left main coronary artery ostial atresia and a review of the literature. Congenital Heart Disease, 14(6), 901923. https://doi.org/10.1111/chd.12842

Angelini, P. (2007). Coronary artery anomalies: An entity in search of an identity. Circulation, 115(10), 1296-1305. https://doi.org/10.1161/CIRCULATIONAHA.106.618082

Angelini, P., Cheong, B. Y., Lenge De Rosen, V. V., Lopez, J. A., Uribe, C., Masso, A. H., Ali, S. W., Davis, B. R., Muthupillai, R., \& Willerson, J. T. (2018). Magnetic Resonance Imaging-Based Screening Study in a General Population of Adolescents. Journal of the American College of Cardiology, 71(5), 579-580. https://doi.org/10.1016/j.jacc.2017.11.051

Angelini, P., Velasco, J. A., \& Flamm, S. (2002). Coronary anomalies: Incidence, pathophysiology, and $\begin{array}{llll}\text { clinical } & \text { relevance. } & \text { Circulation, } & \text { 2449-2454. }\end{array}$ https://doi.org/10.1161/01.CIR.0000016175.49835.57

Angelini, P., Villason, S., Albert Chan, J., \& Diez, J. (1999). Chapter 4: Normal and Anomalous Coronary Arteries in Humans. Part 1: Historical Background. Coronary Artery Anomalies. Retrieved from: https://digitalcommons.library.tmc.edu/angelini/6

Angelini, P., Villason, S., Chan, A. V, \& Diez, G. (1999). Humans.

Baroldi, G., Mantero, O., \& Scomazzoni, G. (1956). The collaterals of the coronary arteries in normal and pathologic hearts. Circulation Research, 4(2), 223-229. https://doi.org/10.1161/01.RES.4.2.223

Barry J. Maron, MD; Jamshid Shirani, MD; Liviu C. Poliac, M. et al. (1996). Sudden Death in Young Competitive Athletes Clinical, Demographic, and Pathological Profiles. JAMA, 276(3). https://doi.org/10.1001/jama.1996.03540030033028

Basso, C., Maron, B. J., Corrado, D., \& Thiene, G. (2000). Clinical profile of congenital coronary artery anomalies with origin from the wrong aortic sinus leading to sudden death in young competitive athletes. Journal of the American College of Cardiology, 35(6), 1493-1501. https://doi.org/10.1016/s0735-1097(00)00566-0

Basso, Cristina, Thiene, G., Mackey-Bojack, S., Frigo, A. C., Corrado, D., \& Maron, B. J. (2009). Myocardial bridging, a frequent component of the hypertrophic cardiomyopathy phenotype, lacks systematic association with sudden cardiac death. European Heart Journal, 30(13), 1627-1634. https://doi.org/10.1093/eurheartj/ehp121

Belviso, I., Angelini, F., Di Meglio, F., Picchio, V., Sacco, A. M., Nocella, C., Romano, V., Nurzynska, D., Frati, G., Maiello, C., Messina, E., Montagnani, S., Pagano, F., Castaldo, C., \& Chimenti, I. (2020). The Microenvironment of Decellularized Extracellular Matrix from Heart Failure Myocardium Alters the Balance between Angiogenic and Fibrotic Signals from Stromal Primitive Cells. International Journal of Molecular Sciences, 21(21). https://doi.org/10.3390/ijms21217903

Belviso, I., Romano, V., Sacco, A. M., Ricci, G., Massai, D., Cammarota, M., Catizone, A., Schiraldi, C., Nurzynska, D., Terzini, M., Aldieri, A., Serino, G., Schonauer, F., Sirico, F., D'Andrea, F., Montagnani, S., Di Meglio, F., \& Castaldo, C. (2020). Decellularized Human Dermal Matrix as a Biological Scaffold for Cardiac Repair and Regeneration. Frontiers in Bioengineering and Biotechnology, 8. https://doi.org/10.3389/fbioe.2020.00229 
Bland, E. F., White, P. D., \& Garland, J. (1933). Congenital anomalies of the coronary arteries: Report of an unusual case associated with cardiac hypertrophy. American Heart Journal, 8(6), 787-801. https://doi.org/10.1016/S0002-8703(33)90140-4

Brown, K. N., \& Borger, J. (2019). Anatomy, Thorax, Heart Anomalous Left Anterior Descending (LAD) Artery. StatPearls, 1-6.

Castaldo, C., Di Meglio, F., Miraglia, R., Sacco, A. M., Romano, V., Bancone, C., Della Corte, A., Montagnani, S., \& Nurzynska, D. (2013). Cardiac fibroblast-derived extracellular matrix (biomatrix) as a model for the studies of cardiac primitive cell biological properties in normal and pathological adult human heart. BioMed Research International, 2013, 352370. https://doi.org/10.1155/2013/352370

Castelletti, S., \& Crotti, L. (2020). To be, or not to be engaged in sport activities, that is the amletic question for patients with coronary artery disease. European Journal of Preventive Cardiology, 27(7), 767-769. https://doi.org/10.1177/2047487319877701

Challoumas, D., Pericleous, A., Dimitrakaki, I. A., Danelatos, C., \& Dimitrakakis, G. (2014). Coronary Arteriovenous Fistulae: A Review. The International Journal of Angiology : Official Publication of the International College of Angiology, Inc, 23(1), 1-10. https://doi.org/10.1055/s-0033-1349162

Corban, M. T., Hung, O. Y., Eshtehardi, P., Rasoul-Arzrumly, E., McDaniel, M., Mekonnen, G., Timmins, L. H., Lutz, J., Guyton, R. A., \& Samady, H. (2014). Myocardial bridging: Contemporary understanding of pathophysiology with implications for diagnostic and therapeutic strategies. Journal of the American College of Cardiology, 63(22), 2346-2355. https://doi.org/10.1016/j.jacc.2014.01.049

Corrado, D., Thiene, G., Nava, A., Rossi, L., \& Pennelli, N. (1990). Sudden death in young competitive athletes: Clinicopathologic correlations in 22 cases. The American Journal of Medicine, 89(5), 588596. https://doi.org/10.1016/0002-9343(90)90176-e

Corrado, Domenico, Basso, C., Rizzoli, G., Schiavon, M., \& Thiene, G. (2003). Does Sports Activity Enhance the Risk of Sudden Death in Adolescents and Young Adults? Journal of the American College of Cardiology, 42(11), 1959-1963. https://doi.org/10.1016/i.jacc.2003.03.002

Corrado, Domenico, Migliore, F., Basso, C., \& Thiene, G. (2006). Exercise and the risk of sudden cardiac death. Herz, 31(6), 553-558. https://doi.org/10.1007/s00059-006-2885-8

D'Andrea, A., Mele, D., Palermi, S., Rizzo, M., Campana, M., Giannuario, G. D., Gimelli, A., Khoury, G., Moreo, A., \& Ospedalieri (ANMCO), a nome dell'Area C. dell'Associazione N. M. C. (2020). Le "zone grigie" degli adattamenti cardiovascolari all'esercizio fisico: Come orientarsi nella valutazione ecocardiografica del cuore d'atleta. Giornale Italiano di Cardiologia, 21(6), 457-468.

Danias, P. G., Stuber, M., McConnell, M. V., \& Manning, W. J. (2001). The diagnosis of congenital coronary anomalies with magnetic resonance imaging. Coronary Artery Disease, 12(8), 621-626. https://doi.org/10.1097/00019501-200112000-00005

De-Giorgio, F., \& Arena, V. (2010). Ostial plication: A rarely reported cause of sudden death. Diagnostic Pathology, 5(1), 1-2. https://doi.org/10.1186/1746-1596-5-15

Desmet, W., Vanhaecke, J., Vrolix, M., Van De Werf, F., Piessens, J., Willems, J., \& De Geest, H. (1992). Isolated single coronary artery: A review of 50000 consecutive coronary angiographies. European Heart Journal, 13(12), 1637-1640. https://doi.org/10.1093/oxfordjournals.eurheartj.a060117

Dodge-Khatami, A., Mavroudis, C., \& Backer, C. L. (2002). Anomalous origin of the left coronary artery from the pulmonary artery: Collective review of surgical therapy. Annals of Thoracic Surgery, 74(3), 946-955. https://doi.org/10.1016/S0003-4975(02)03633-0

Dotan, M., Roguin, A., Sinyor, D., Yalonetsky, S., Asaad, K., Schwartz, Y., Khatib, I., \& Lorber, A. (2013). Increased incidence of coronary artery origin anomalies associated with isolated patent ductus arteriosus. Pediatric Cardiology, 34(4), 907-911. https://doi.org/10.1007/s00246-012-0569-0 
Edwards, C. P., Yavari, A., Sheppard, M. N., \& Sharma, S. (2010). Anomalous coronary origin: The challenge in preventing exercise-related sudden cardiac death. British Journal of Sports Medicine, 44(12), 895-897. https://doi.org/10.1136/bjsm.2008.054387

Edwards, J. E., \& Vlodaver, Z. (1971). Pathology of Coronary Atherosclerosis. Progress in Cardiovascular Diseases, XIV(3). https://doi.org/10.1016/0033-0620(71)90023-5

Ferreira, A. G., Trotter, S. E., Konig, B., Decourt, L. V., Fox, K., \& Olsen, E. G. J. (1991). Myocardial bridges: Morphological and functional aspects. British Heart Journal, 66(5), 364-367. https://doi.org/10.1136/hrt.66.5.364

Frescura, C., Basso, C., Thiene, G., Corrado, D., Pennelli, T., Angelini, A., \& Daliento, L. (1998). Anomalous origin of coronary arteries and risk of sudden death: A study based on an autopsy population of congenital heart disease. Human Pathology, 29(7), 689-695. https://doi.org/10.1016/S0046-8177(98)90277-5

Geuns, R. J. M., \& Cademartiri, F. (2005). Anatomy of the Coronary Arteries and Veins in CT Imaging. CT of the Heart, 3, 219-227. https://doi.org/10.1385/1-59259-818-8:219

Ghosh PK, Agarwal SK, Kumar R, Chandra N, P. VK. (1994). Anomalous origin of right coronary artery from left aortic sinus. J Cardiovasc Surg (Torino), feb(32), 65-70.

Gowda, R. M., Vasavada, B. C., \& Khan, I. A. (2006). Coronary artery fistulas: Clinical and therapeutic

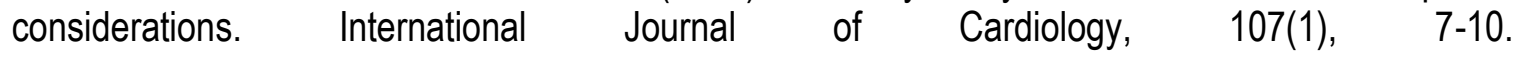
https://doi.org/10.1016/j.ijcard.2005.01.067

Gräni, C., Benz, D. C., Steffen, D. A., Giannopoulos, A. A., Messerli, M., Pazhenkottil, A. P., Gaemperli, O., Gebhard, C., Schmied, C., Kaufmann, P. A., \& Buechel, R. R. (2018). Sports Behavior in MiddleAged Individuals with Anomalous Coronary Artery from the Opposite Sinus of Valsalva. Cardiology (Switzerland), 139(4), 222-230. https://doi.org/10.1159/000486707

Harmon, K. G., Asif, I. M., Maleszewski, J. J., Owens, D. S., Prutkin, J. M., Salerno, J. C., Zigman, M. L., Ellenbogen, R., Rao, A. L., Ackerman, M. J., \& Drezner, J. A. (2015). Incidence, cause, and comparative frequency of sudden cardiac death in national collegiate athletic association athletes a $\begin{array}{llll}\text { decade in } \quad \text { review. } & \text { Circulation, } & 132(1), & 19-19 .\end{array}$ https://doi.org/10.1161/CIRCULATIONAHA.115.015431

Heart, A., Liberthson, R. R., Sagar, K., Berkoben, J. P., Weintraub, R. M., \& Levine, F. H. (2010). Cir cAln Official Journal of the Congenital Coronary Arteriovenous Fistula. Circulation, 59(5), 849-854. https://doi.org/10.1161/01.CIR.59.5.849

Kim, M. S., Jung, J. I., \& Chun, H. J. (2010). Coronary to pulmonary artery fistula: Morphologic features at multidetector CT. International Journal of Cardiovascular Imaging, 26(SUPPL. 2), 273-280. https://doi.org/10.1007/s10554-010-9711-3

Kim, S. Y., Seo, J. B., Do, K. H., Heo, J. N., Lee, J. S., Song, J. W., Choe, Y. H., Kim, T. H., Yong, H. S., Choi, S. II, Song, K. S., \& Lim, T. H. (2006). Coronary artery anomalies: Classification and ECGgated multi-detector row CT findings with angiographic correlation. Radiographics, 26(2), 317-333. https://doi.org/10.1148/rg.262055068

Kugelmass, A. D., Manning, W. J., Piana, R. N., Weintraub, R. M., Baim, D. S., \& Grossman, W. (1992). Coronary arteriovenous fistula presenting as congestive heart failure. Catheterization and Cardiovascular Diagnosis, 26(1), 19-25. https://doi.org/10.1002/ccd.1810260106

Kumari, M., Rha, S.-W., Poddar, K. L., Park, J. Y., Choi, B. G., Kim, Y. K., Na, J. O., Choi, C. U., Lim, H. E., Kim, J. W., Kim, E. J., Park, C. G., Seo, H. S., \& Oh, D. J. (2011). Clinical and Angiographic Characteristics of Coronary Endothelial Dysfunction Severity in Patients With Myocardial Bridge As Assessed By Acetylcholine Provocation Test. Journal of the American College of Cardiology, 57(14), E1513. https://doi.org/10.1016/s0735-1097(11)61513-1 
Lange, R., Vogt, M., Hörer, J., Cleuziou, J., Menzel, A., Holper, K., Hess, J., \& Schreiber, C. (2007). Long-Term Results of Repair of Anomalous Origin of the Left Coronary Artery From the Pulmonary $\begin{array}{llll}\text { Artery. Annals of } \quad \text { Thoracic } & \text { 83(4), }\end{array}$ https://doi.org/10.1016/j.athoracsur.2006.11.005

Latson, L. A. (2007). Coronary artery fistulas: How to manage them. Catheterization and Cardiovascular Interventions, 70(1), 111-118. https://doi.org/10.1002/ccd.21125

Lipton, M. J., Barry, W. H., Obrez, I., Silverman, J. F., \& Wexler, L. (1979). Isolated single coronary artery: Diagnosis, angiographic classification, and clinical significance. Radiology, 130(1), 39-47. https://doi.org/10.1148/130.1.39

Luo, L., Kebede, S., Wu, S., \& Stouffer, G. A. (2006). Coronary artery fistulae. American Journal of the Medical Sciences, 332(2), 79-84. https://doi.org/10.1097/00000441-200608000-00005

Macdonald, H. M., Nishiyama, K. K., Kang, J., Hanley, D. A., \& Boyd, S. K. (2011). Age-related patterns of trabecular and cortical bone loss differ between sexes and skeletal sites: A population-based HRpQCT study. Journal of Bone and Mineral Research: The Official Journal of the American Society for Bone and Mineral Research, 26(1), 50-62. https://doi.org/10.1002/jbmr.171

Mangukia, C. V. (2012). Coronary artery fistula. Annals of Thoracic Surgery, 93(6), 2084-2092. https://doi.org/10.1016/j.athoracsur.2012.01.114

Maron, B. J., Doerer, J. J., Haas, T. S., Tierney, D. M., \& Mueller, F. O. (2009). Sudden deaths in young competitive athletes analysis of 1866 deaths in the united states, 1980-2006. Circulation, 119(8), 1085-1092. https://doi.org/10.1161/CIRCULATIONAHA.108.804617

McNamara JJ, G. R. (1969). Congenital coronary artery fistula. Surgery.

Moore, A. G., \& Agarwal, P. P. (2014). Hammock sign. Journal of Thoracic Imaging, 29(5), W89. https://doi.org/10.1097/RTI.0000000000000095

Morales, A. R., Romanelli, R., Tate, L. G., Boucek, R. J., \& de Marchena, E. (1993). Intramural left anterior descending coronary artery: Significance of the depth of the muscular tunnel. Human Pathology, 24(7), 693-701. https://doi.org/10.1016/0046-8177(93)90004-Z

Morgan, J. R., Forker, A. D., O'Sullivan, M. J., \& fosburg, R. G. (1972). Coronary arterial fistulas. Seven cases with unusual features. The American Journal of Cardiology, 30(4), 432-436. https://doi.org/10.1016/0002-9149(72)90578-4

Nieman, K., Oudkerk, M., Rensing, B. J., van Ooijen, P., Munne, A., van Geuns, R. J., \& de Feyter, P. J. (2001). Coronary angiography with multi-slice computed tomography. Lancet (London, England), 357(9256), 599-603. https://doi.org/10.1016/S0140-6736(00)04058-7

Olivotto, I., Cecchi, F., \& Yacoub, M. H. (2009). Myocardial bridging and sudden death in hypertrophic cardiomyopathy: Salome drops another veil. European Heart Journal, 30(13), 1549-1550. https://doi.org/10.1093/eurheartj/ehp216

Palermi, S., Sacco, A. M., Belviso, I., Romano, V., Montesano, P., Corrado, B., \& Sirico, F. (2020). Guidelines for Physical Activity-A Cross-Sectional Study to Assess Their Application in the General Population. Have We Achieved Our Goal? International Journal of Environmental Research and Public Health, 17(11). https://doi.org/10.3390/ijerph17113980

Qureshi, S. A. (2006). Coronary arterial fistulas. Orphanet Journal of Rare Diseases, 1(1), 2-7. https://doi.org/10.1186/1750-1172-1-51

Ricci, F., Aung, N., Gallina, S., Zemrak, F., Fung, K., Bisaccia, G., Paiva, J. M., Khanji, M. Y., Mantini, C., Palermi, S., Lee, A. M., Piechnik, S. K., Neubauer, S., \& Petersen, S. E. (2020). Cardiovascular magnetic resonance reference values of mitral and tricuspid annular dimensions: The UK Biobank cohort. Journal of Cardiovascular Magnetic Resonance, 23(1), 5. https://doi.org/10.1186/s12968$\underline{020-00688-y}$ 
Ricci, F., Sutton, R., Palermi, S., Tana, C., Renda, G., Gallina, S., Melander, O., De Caterina, R., \& Fedorowski, A. (2018). Prognostic significance of noncardiac syncope in the general population: A systematic review and meta-analysis. Journal of Cardiovascular Electrophysiology, 29(12), 16411647. https://doi.org/10.1111/jce.13715

Rittenhouse, E. A., Doty, D. B., \& Ehrenhaft, J. L. (1975). Congenital Coronary Artery-Cardiac Chamber Fistula: Review of Operative Management. Annals of Thoracic Surgery, 20(4), 468-485. https://doi.org/10.1016/S0003-4975(10)64245-2

Roberts, W. C. (1986). Major anomalies of coronary arterial origin seen in adulthood. American Heart Journal, 111(5), 941-963. https://doi.org/10.1016/0002-8703(86)90646-0

Shiga, Y., Tsuchiya, Y., Yahiro, E., Kodama, S., Kotaki, Y., Shimoji, E., Fukuda, N., Morito, N., Urata, M., Saito, N., Niimura, H., Mihara, H., Yamanouchi, Y., \& Urata, H. (2008). Left main coronary trunk connecting into right atrium with an aneurysmal coronary artery fistula. International Journal of Cardiology, 123(2), 28-30. https://doi.org/10.1016/j.ijcard.2006.11.108

Sorajja, P., Ommen, S. R., Nishimura, R. A., Gersh, B. J., Tajik, A. J., \& Holmes, D. R. (2003). Myocardial bridging in adult patients with hypertrophic cardiomyopathy. Journal of the American College of Cardiology, 42(5), 889-894. https://doi.org/10.1016/S0735-1097(03)00854-4

Swensonn R.E., Murillo-Olivas A., Elias W., et al. (1988). Non invasive Doppler Color flow mapping for detection of anomalous origin of the fet coronary artery from the pulmonary artery and for evaluation of surgical repair. J Am Coll Cardiol. https://doi.org/10.1016/0735-1097(88)91546-X

Tio, R. A., Van Gelder, I. C., Boonstra, P. W., \& Crijns, H. J. G. M. (1997). Myocardial bridging in a survivor of sudden cardiac near-death: Role of intracoronary Doppler flow measurements and angiography during dobutamine stress in the clinical evaluation. Heart, 77(3), 280-282. https://doi.org/10.1136/hrt.77.3.280

Van Hare, G. F., Ackerman, M. J., Evangelista, J.-A. K., Kovacs, R. J., Myerburg, R. J., Shafer, K. M., Warnes, C. A., Washington, R. L., \& American Heart Association Electrocardiography and Arrhythmias Committee of Council on Clinical Cardiology, Council on Cardiovascular Disease in Young, Council on Cardiovascular and Stroke Nursing, Council on Functional Genomics and Translational Biology, and American College of Cardiology. (2015). Eligibility and Disqualification Recommendations for Competitive Athletes With Cardiovascular Abnormalities: Task Force 4: Congenital Heart Disease: A Scientific Statement From the American Heart Association and American College of Cardiology. Circulation, 132(22), e281-291. https://doi.org/10.1161/CIR.0000000000000240

Vavuranakis, M., Bush, C. A., \& Boudoulas, H. (1995). Coronary artery fistulas in adults: Incidence, angiographic characteristics, natural history. Catheterization and Cardiovascular Diagnosis, 35(2), 116-120. https://doi.org/10.1002/ccd.1810350207

Villa, A. D., Sammut, E., Nair, A., Rajani, R., Bonamini, R., \& Chiribiri, A. (2016). Coronary artery anomalies overview: The normal and the abnormal. World Journal of Radiology, 8(6), 537. https://doi.org/10.4329/wir.v8.i6.537

Virmani, R., Chun, P. K. C., Goldstein, R. E., Robinowitz, M., \& Mcallister, H. A. (1984). Acute takeoffs of the coronary arteries along the aortic wall and congenital coronary ostial valve-like ridges: Association with sudden death. Journal of the American College of Cardiology, 3(3), 766-771. https://doi.org/10.1016/S0735-1097(84)80253-3

Vitarelli, A., De Curtis, G., Conde, Y., Colantonio, M., Di Benedetto, G., Pecce, P., De Nardo, L., \& Squillaci, E. (2002). Assessment of congenital coronary artery fistulas by transesophageal color Doppler echocardiography. American Journal of Medicine, 113(2), 127-133. https://doi.org/10.1016/S0002-9343(02)01157-9 
Wesselhoeft H, Fawcett JS, J. AL. (1968). Anomalous origin of the left coronary artery from the pulmonary trunk: Its clinical spectrum, pathology and pathophysiology, based on review of 140 cases with seven further cases. https://doi.org/10.1161/01.cir.38.2.403

Yamanaka, O., \& Hobbs, R. E. (1990). Coronary artery anomalies in 126,595 patients undergoing coronary arteriography. Catheterization and Cardiovascular Diagnosis, 21(1), 28-40. https://doi.org/10.1002/ccd.1810210110

Yu, R., Sharma, B., \& Franciosa, J. A. (1986). Acquired coronary artery fistula to the left ventricle after acute myocardial infarction. The American Journal of Cardiology, 58(6), 557-558. https://doi.org/10.1016/0002-9149(86)90036-6

Yurtdas Mustafa, \& Gülen Oktay. (2012). Anomalous origin of the right coronary artery from the left anterior descending artery: Review of the literature. Cardiology Journal, 19(2), 122-129. https://doi.org/10.5603/CJ.2012.0023

Zeppilli, P. (1983). Med Sport-Miti e pregiudizi sulla morte improvvisa da sport.

\section{(9) $\odot \Theta \Theta$}

This work is licensed under a Attribution-NonCommercial-NoDerivatives 4.0 International (CC BY-NC-ND 4.0). 